\title{
DYNAMICS OF SOME ENZYME IMMUNOASSAY PARAMETERS IN ISCHEMIC STROKE IN CHILDREN
}

\author{
Mariana SPRINCEAN ${ }^{1,2} \bowtie$, Svetlana HADJIU1,2, Cornelia CALCII ${ }^{1,2}$, Nadejda LUPUSOR $^{1,2}$, \\ Eugenia CRIVCEANSCAIA ${ }^{2}$, Stanislav GROPPA ${ }^{1,3}$, Ninel REVENC $0^{1,2}$
}

${ }^{1}$ State University of Medicine and Pharmacy "Nicolae Testemitanu“, Chisinau, Republic of Moldova

2 Public Health Medical Institution Mother and Child Institute, Chisinau, Republic of Moldova

${ }^{3}$ National Epilepsy Center, Chisinau, Republic of Moldova

Received 07 Sept 2020, Accepted 03 Nov 2020

https://doi.org/10.31688/ABMU.2020.55.4.01

\begin{abstract}
Introduction. Ischemic stroke (IS) is a rare, but underestimated disease in children. The incidence of IS is 2-13:100000 children or 1:4000 in neonatal period. The objective of the study was the evaluation of the expressivity of immune parameters in children with IS, to improve understanding of pathogenesis, early diagnosis and predictive factors of the disease.

Materials and methods. We performed a prospective study between 2017-2019 in the Republic of Moldova, on a sample of 53 children with IS (study sample, SS), investigated by ELISA in the acute phase, determining the serum levels of S100B protein, vascular endothelial growth factor (VEGF) and ciliary neurotrophic factor (CNTF). These markers were also appreciated in 53 "practically healthy" children (control sample, CS). Six months after IS, serum levels of VEGF and S100B were re-assessed.

Results. The mean values of markers in the acute phase were as follows: (1) S100B $0.524 \pm 0.0850 \mathrm{ng} / \mathrm{mL}$ (Fisher's test 9.330, p<0.01); (2) VEGF 613.41 \pm 39.299 $\mathrm{pg} / \mathrm{mL}$ (Fisher's test 60.701, p<0.001); (3) CNTF $7.84 \pm 0.322 \mathrm{pg} / \mathrm{mL}$ (Fisher's test 32.550, $\mathrm{p}<0.001$ ), which were significantly different from the levels in CS.

\section{Résumé}

Dynamique de certains paramètres immuno-enzymatiques en cas d'AVC ischémique chez les enfants

Introduction. L'accident vasculaire ischémique (AVCI) est une maladie rare mais sous-estimée chez les enfants. L'incidence de l'AVCI est de 2 à 13 :100 000 enfants, ou 1:4000 en période néonatale.

Objectif: l'évaluation de l'expression des paramètres immunitaires aux enfants atteints d'AVCI pour améliorer la compréhension de la pathogenèse, le diagnostic précoce et les facteurs prédictifs de la maladie.

Matériaux et méthodes. En 2017-2019, dans la République de Moldova, une étude prospective a été menée sur un échantillon de 53 enfants atteints d'AV. CI (échantillon d'étude, EE), étudiée conformément à l'ELISA dans la phase aiguë de la maladie, et qui a déterminé les taux sériques de la protéine S100B, le facteur de croissance de l'endothélium vasculaire (VEGF) et le facteur neurotrophique ciliaire (CNTF). Ces marqueurs ont également été appréciés chez 53 enfants " en bonne santé» (échantillon témoin, ET). Six mois après l'AVCI, les taux sériques de VEGF et de S100B ont été réévalués.
\end{abstract}


Conclusions. In the acute period of IS we observed a significant increase of values of certain markers (S100B, VEGF and CNTF), which determine their role as biomarkers involved in ischemic brain processes. It is necessary to carry out new longitudinal studies in children with IS to improve the diagnosis and treatment.

Keywords: biomarkers, ischemic stroke, children.

\author{
Abbreviations: \\ Ischemic stroke - IS \\ S100B protein - S100B \\ Vascular endothelial growth factor - VEGF \\ Ciliary neurotrophic factor - CNTF \\ Study sample - SS \\ Control sample - CS \\ F - Fisher's test
}

\section{INTRODUCTION}

Stroke in children is a major neurological emergency, being an important cause of morbidity and mortality ${ }^{1}$. Stroke can be detected in the neonatal period in one of 2500 - 4000 live newborns, and in children over one month of age it occurs in 1.2 to 8 per $100000^{2}$. The clinical features of stroke in children are different from those in adults and are often obscure or variable depending on the age of the child. Thus, in young children, stroke manifestations may be associated with nonspecific neurological symptoms, seizures, rarely with motor problems or speech and sensitivity disorders. Similarly, stroke may develop during pregnancy or immediately after birth, without significant neurological symptoms ${ }^{3}$. Mortality in pediatric stroke is high, with a rate between 5 and $10 \%{ }^{4}$. If therapeutic measures are not taken in the acute period, more than half of survivors have long-term neurological sequelae, and 10\% to $20 \%$ present stroke relapses. These patients require medical assistance in centers of urgent care and rehabilitation for pediatric patients with stroke, as well as a multidisciplinary approach for the purpose of highly specialized diagnosis and treatment ${ }^{5}$. Thus, stroke in children imposes significant demands on the health system, the families and community.

Ischemic stroke (IS) is caused by a focal disorder of cerebral circulation, secondary to ruptures of arteries or veins or embolization, requiring confirmation by neuroimaging examinations. The early clinical manifestations are variable, as IS in children can occur during various periods of development, e. g., prenatal, perinatal and postnatal ${ }^{1}$.
Résultats. Les valeurs moyennes des marqueurs en phase aiguë étaient les suivantes : (1) S100B $0.524 \pm 0.0850 \mathrm{ng} / \mathrm{mL}$ (test de Fisher 9.330, $\mathrm{p}<0.01$ ); (2) VEGF 613.41 $\pm 39.299 \mathrm{pg} / \mathrm{mL}$ (test de Fisher 60.701, p <0.001); (3) CNTF 7.84 $\pm 0.322 \mathrm{pg} / \mathrm{mL}$ (test de Fisher $32.550, \mathrm{p}<0.001$ ), qui étaient significativement différents des niveaux détectés chez les «enfants en bonne santé».

Conclusions. Dans la période aiguë de l'AVCI, on a observé une augmentation significative des valeurs de marqueurs, qui déterminent leur rôle en tant que biomarqueurs impliqués dans les processus cérébraux ischémiques. Il est nécessaire de mener de nouvelles études longitudinales chez les enfants atteints d'AVCI pour améliorer le diagnostic et le traitement.

Mots-clés: biomarqueurs, accident vasculaire cérébral ischémique, enfants.

In IS, regardless of etiology, the death of neurons is associated with a decrease in the blood flow and therefore oxygen and glucose in the brain tissue. The degree of increase in vessel density in the ischemic penumbra is positively correlated with the survival rate of stroke patients. In addition, increased angiogenesis has been associated with improved functional outcomes in both animal models and stroke patients ${ }^{6}$. These aspects have been analyzed by some studies, noting that neuroinflammatory mechanisms are associated with severe motor sequelae, which occur after IS ${ }^{6}$.

Neuroinflammation represents one of the main mechanisms of onset and development of IS. In this context, it is suggested the importance of assessing the serum level of inflammatory markers, involved in the pathogenesis and onset of IS, which may be of great importance for recovery. Clinical studies and investigations by researchers in the field have shown that inflammatory responses after IS in children are different from those in adults?

According to data from several authors, the major role of biomarkers has been substantiated in pathogenesis, diagnosis and neurological outcome, and recovery of children with IS is also highlighted in the literature on biological molecular topics. The list of biomarkers includes some inflammatory markers, e.g., pro-inflammatory cytokines such as IL-6, IL-1 $\beta$, but also other substances and other biological factors, including vascular endothelial growth factor (VEGF), ciliary neurotrophic factor (CTF), S100B protein, CD105 endoglin, antiphospholipid antibodies (APA) etc ${ }^{7,8}$.

The obJective of the Study was the evaluation of immune parameters in children with IS, to improve 
understanding of pathogenesis, early diagnostic and predictive factors of the disease.

\section{Materials AND Methods}

We performed a prospective study between 2017 - 2019 in the Republic of Moldova, within the framework of the State Program "Systemogenesis of Risk Factors, Optimization of Health Care Service, Sustainable Evaluation and Mathematical Modeling of Stroke", with the project for children: "Evaluation incidence, prevalence, risk factors, and research of clinical, neuroimaging, neurophysiological and neurotrophic management of strokes in children". Based on this project, we conducted a prospective study on a sample of 53 children diagnosed with IS, who have been examined and consulted at the Institute of Mother and Child, Chisinau, Republic of Moldova. The study group comprises 53 children, i.e., 29 boys and 24 girls with IS diagnosed during the given period. We obtained data about the history of the patient, i.e. prenatal history, mother's diseases, course of pregnancy, perinatal and postnatal history, neurological status and general somatic status, results of neurological investigations, i.e. ultrasound of the nervous system and electroencephalography, as well as neurological imaging methods, i. e., magnetic resonance imaging and cerebral computed tomography.

The criteria for inclusion in the study were: (1) ischemic stroke; (2) children aged from birth to 18 years; (3) signed informed consent of parents. The exclusion criteria were: (1) hemorrhagic stroke; (2) cavernous sinus thrombosis; (3) age over 18 years; (4) acute craniocerebral trauma; (5) lack of informed parental consent.

The age of children with IS included in the study ranged from birth to 18 years, mean age $5.1 \pm 2.3$ years. In the 53 patients with IS (study sample, SS), during the acute period of the disease, serum levels of some enzyme immunoassay markers were assessed by ELISA, including S100B protein, vascular endothelial growth factor (VEGF) and ciliary neurotrophic factor (CNTF). As reference values, there were considered the serum levels of the above-mentioned markers in a sample of 53 "practically healthy" children (control sample, CS). Similarly, serum values of VEGF and S100B were assessed over 6 months after IS. Initially, clinical symptoms of IS were registered, followed by imaging findings, as well as venous blood sampling with centrifugation, separation of serum for storage at $\left(-20^{\circ} \mathrm{C}\right)$. In the samples, it was determined the serum concentration of the above biomarkers. Enzyme immunoassay was carried out using ELISA method at the SYNERGY-H1 analyzer (USA, BioTek). The results were analyzed using statistical methods of determining frequencies, confidence interval, averages with standard deviation and standard error, as well as Pearson correlation, compared to the chi-square, the T-Student test, i.e., the possibility of matching the results in the sample with the results of general population, as the statistical method used ( $\mathrm{p}$ value considered statistically significant). The approval of ethical aspects and consent to participate in the study was carried out in accordance with the protocol No 69 dated March 21, 2017, which was approved by the Research Ethic Board of State University of Medicine and Pharmaceutics Nicolae Testemitanu, Chisinau, Republic of Moldova.

\section{Results}

We determined the serum concentration of several biomarkers, including S100B protein, VEGF and CNTF in patients with IS during the acute phase of the disease. Similarly, 6 months after the stroke, we determined VEGF and S100B. The serum concentration of inflammatory markers was appreciated to determine their involvement in the mechanisms of angiogenesis and vasculo-genesis, as well as the correlation of the inflammatory markers values with the degree of CNS impairment, depending on the stage of the pathological process and the child's age.

The S100B protein belongs to the S-100 protein family, being related to the group of calcium-binding proteins $\mathrm{S} 100$ which is produced in glial cells, mainly in astrocytes, but also outside the central nervous system (CNS), e.g., in adipocytes. Its release into biological fluids and short half-life make it a very good marker for acute brain tissue lesions, i.e., brain trauma, ischemic or hemorrhagic stroke ${ }^{11}$. The normal serum level of this protein allows to exclude a severe CNS pathology ${ }^{12}$. Some studies have shown that S100B can be released from damaged cells and enter the extracellular compartment or bloodstream ${ }^{11}$. Serum levels of the S100B protein increase in the acute phase of brain damage.

The level of the S100B protein in the acute phase of the disease is higher in SS than in the CS. In SS the mean value of $S 100 B$ was $0.524 \pm 0.0850 \mathrm{ng} /$ $\mathrm{mL}$, with a maximum value of $4.390 \mathrm{ng} / \mathrm{mL}$, while in CS the mean level was $0.120 \pm 0.0038 \mathrm{ng} / \mathrm{mL}$ and the maximum level $0.149 \mathrm{ng} / \mathrm{mL}$, which shows a statistically significant difference between samples ( $\mathrm{F}=9.330$, $\mathrm{p}<0.01$ ) (Fig. 1).

The highest values of S100B were found in children with severe IS, which suggests the involvement of this protein in the plasticity of neurons and axonal proliferation even from the acute period of the disease, and its involvement in pro-inflammatory processes. At the same time, $\mathrm{S} 100 \mathrm{~B}$ protein participates at 


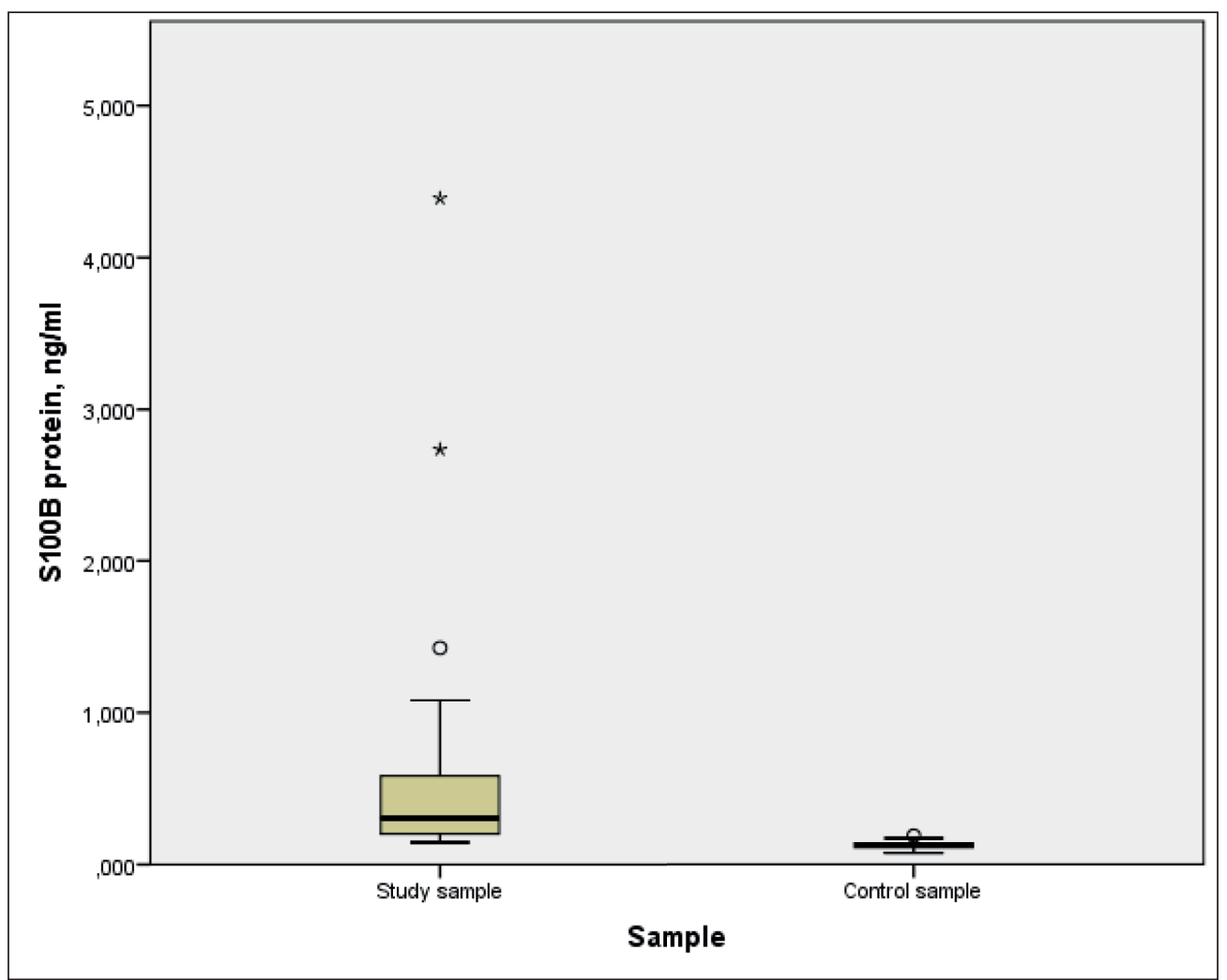

Figure 1. Serum levels of S100B proteins in children with IS compared to the sample of "practically healthy" children, $\mathrm{ng} / \mathrm{mL}$.

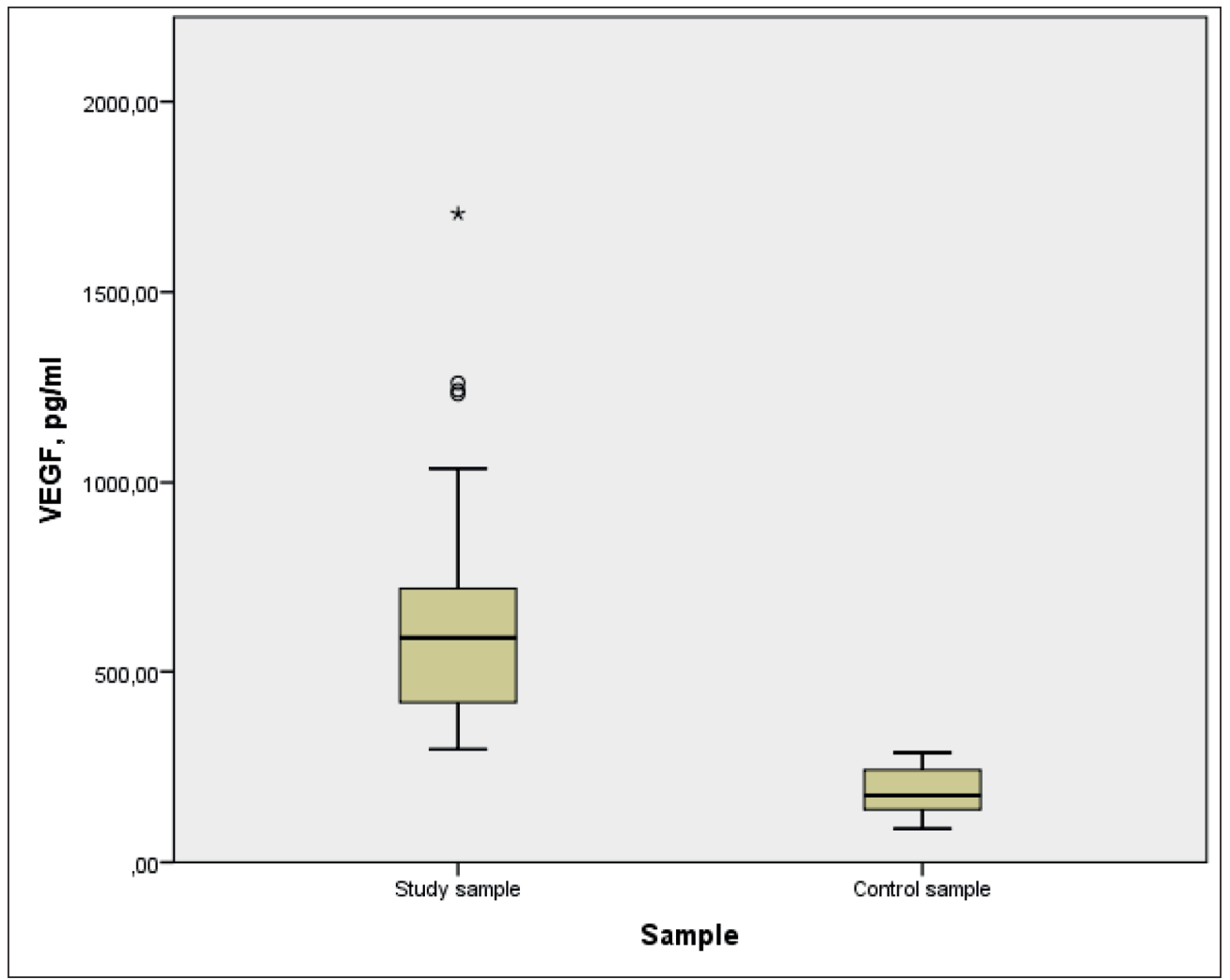

Figure 2. Serum levels of VEGF protein in children with IS compared to the sample of "practically healthy" children, $\mathrm{pg} / \mathrm{mL}$. 
stimulating the influx of $\mathrm{Ca}^{2+}$, which can promote cellular intoxication and stimulate epileptoid genesis. In this context, the assessment of S100B protein derived from the astroglia is considered not only as a potential quantitative objective prognostic marker of ischemic brain lesions, but also as a reliable screening tool for identifying patients having the worst remote neurological outcome. Moreover, the higher the S100 B protein values in the onset period of IS, the more serious the patient's condition $\left(\mathrm{r}_{\mathrm{xy}}=0.786\right)$ and the higher the risk of developing neurological complications.

The group of vascular endothelial growth factors (VEGF) is known for regulating vascularization and stimulating the formation of blood vessels. In the brain, VEGF act as important regulatory factors of angiogenesis, neuro protection and neurogenesis. VEGF can contribute to collateral ischemic remodeling and have recently been shown as a biomarker of IS. VEGF are involved in both vasculo-genesis, e.g., de novo formation of the embryonic circulatory system, as well as in angiogenesis, e.g., extensive growth of blood vessels after pre-existing vasculitis. In the acute phase of IS, the increase of VEGF level induces damage to the blood-brain barrier and vascular leakage, which leads to disruption of homeostasis, invasion of peripheral immune cells and edema. These harmful effects of VEGF on the integrity of vessels are transient, since after the acute phase elevated VEGF have a neuroprotective effect.

Increased VEGF values at the onset of IS, as showed in the literature, is one of the main mediators of cerebral angiogenesis; our data suggest that this level has been significantly higher in SS, i.e., $613.41 \pm 39.299 \mathrm{pg} / \mathrm{mL}$, with a minimum value of $296.23 \mathrm{pg} / \mathrm{mL}$, reaching a maximum value of 1705.81 $\mathrm{pg} / \mathrm{mL}$ in some patients, compared to CS where the average VEGF level was of $185.50 \pm 12.039 \mathrm{pg} / \mathrm{L}$, with a maximum value of $287.44 \mathrm{pg} / \mathrm{mL}$, lower than the minimum level of this factor recorded in SS. The observed difference between two samples was statistically significant $(F=60.701, p<0.001)$ (Fig. 2).

The excessive increase in VEGF levels suggests damage to the blood-brain barrier and severe disorder of homeostasis, with a massive invasion of peripheral immune cells and the development of cerebral edema in the early stage of IS. In children with a severe form of IS, VEGF levels were extremely high, and these patients often develop seizures and severe motor deficit. Therefore, VEGF can be considered an important marker of IS severity in children, and increased VEGF levels correlate with the severity of the disease $\left(r_{x y}=0.698\right)$. VEGF was recently associated with the CNTF as an important biomarker in stroke?

CNTF is a pleiotropic cytokine from the CNS cytokines group. CNTF contributes to the survival of nerve cells in degenerative diseases and promotes axonal growth? It is an important biomarker in many neurological diseases, including IS in children, being a significant factor in the survival of neurons and oligodendrocytes, mediates neurogenesis and anti-inflammatory processes ${ }^{8}$. The increase in serum levels of CNTF in the acute period of IS in children suggests the involvement of this factor in stroke-induced neurogenesis and in the pro-inflammatory processes that occur related to this condition. Increased serum levels of CNTF are known to be in direct correlation with the degree of impairment of the brain structures $^{7}$. In children from SS, an average CNTF level of $7.84 \pm 0.322 \mathrm{pg} / \mathrm{mL}$ was obtained, having a very wide variation in peak values from $5.46 \mathrm{pg} / \mathrm{mL}$ to 20.26 $\mathrm{pg} / \mathrm{mL}$. In CS the mean value was $5.29 \pm 0.067 \mathrm{pg} /$ $\mathrm{mL}$, with variation within smaller limits from 4.94 $\mathrm{pg} / \mathrm{mL}$ to $5.90 \mathrm{pg} / \mathrm{mL},(\mathrm{F}=32.550, \mathrm{p}<0.001)$ (Fig. 3).

Thus, the assessment of the CNTF level in children with IS provides a background for the research of therapeutic strategies for IS in children. In our study, it was observed a strong inverse correlation between the CNTF levels and the severity of IS $\left(r_{x y}\right.$ $=-0.72$ ), and in "practically healthy" children no such correlation was found $\left(r_{x y}=0.208\right)$. Thus, the obtained results suggest the role of the CNTF in the mediation of anti-inflammatory and neuro- regeneration processes and the promotion of neuropasticity, starting from the initial stages of IS.

The present study showed that serum levels of S100B, VEGF, CNTF are significantly increased in children with severe stroke $(\mathrm{p}<0.001)$. The more severe the degree of CNS impairment, the more prominent the increase in serum concentrations of respective biomarkers.

The analysis of the data (Fig. 4) showed that one of the major biomarkers of acute IS is the protein S100B. The relative ratio of the maximum values of S100B detected in acute IS/the data obtained in those without the disease was 29.46 times higher, and the average values were 4.36 times higher in the acute phase of IS. These results showed that S100B is one of the most sensitive biomarkers that reacts promptly in acute IS, which can act to maintain inflammatory processes, and the wide variability of its levels is dependent on the severity of brain damage. The elevated level of this interleukin shows the persistence of inflammatory processes which lead to injury of the brain tissue. An even lower ratio of the maximum values of other biomarkers was found in acute IS phase compared to "practically healthy" children "virtually healthy", but the comparative analysis of the medium values shows sensibility also in the case of VEGF (5.93/3.31, respectively) and CNTF $(3.43 ; 1.48$, respectively) to lesion processes, their 


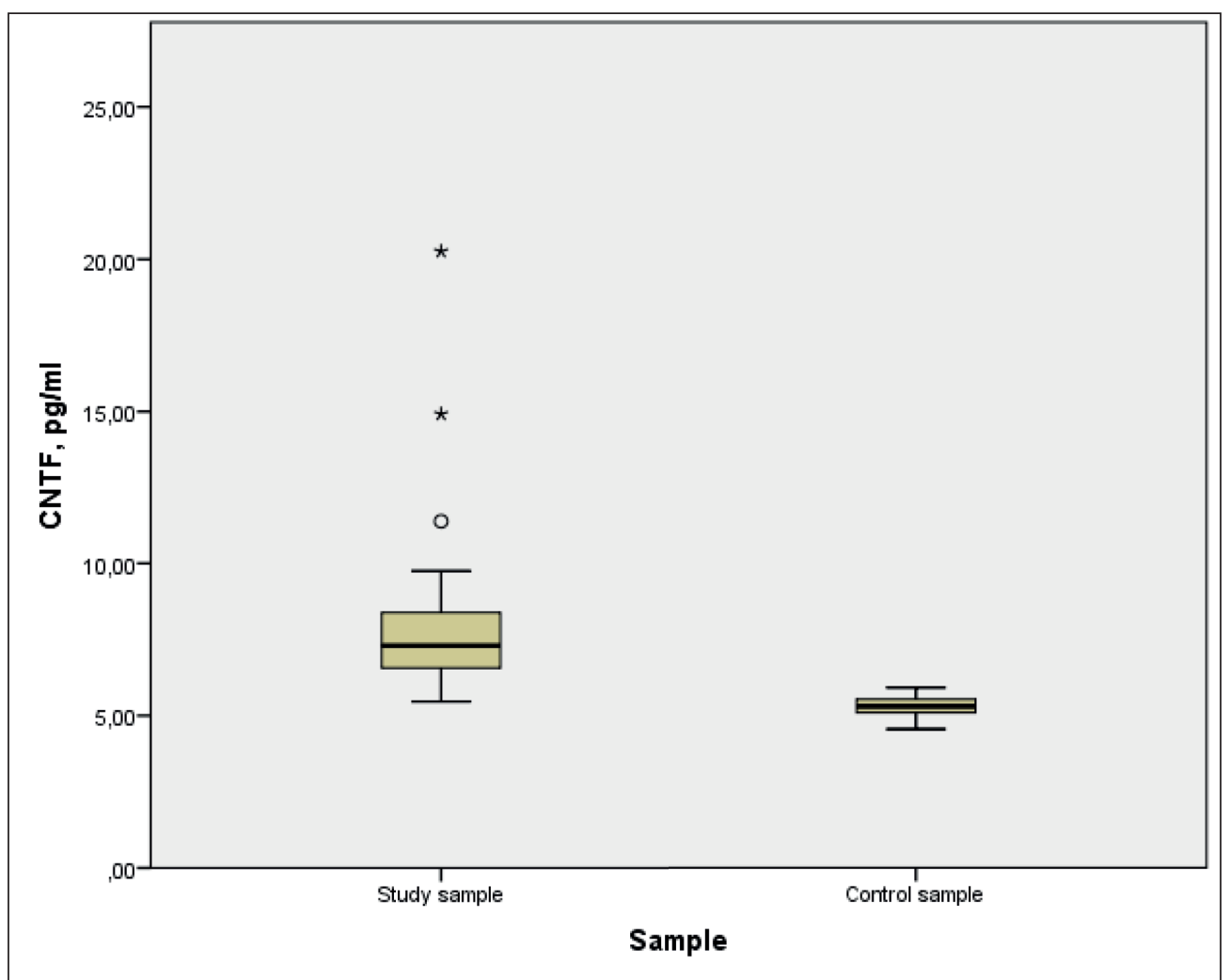

Figure 3. Serum levels of CNTF protein in children with IS compared to the sample of "practically healthy" children, $\mathrm{pg} / \mathrm{mL}$.

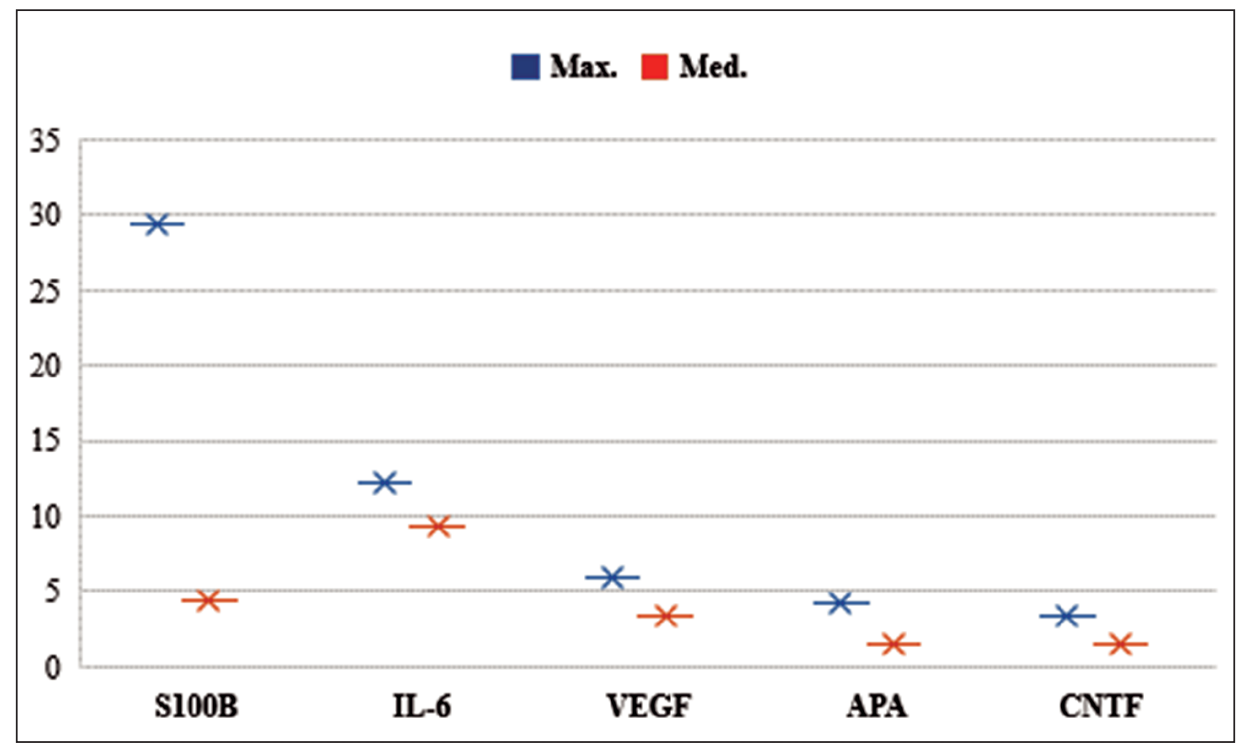

Figure 4. Relative ratio of the maximum and average values of some markers of the acute phase of IS biomarkers in the acute period of the disease compared to the sample of "practically healthy" children.

involvement in the pro-inflammatory mechanisms of the disease, and in the promotion of auto- and neuroimmune processes, which can be triggered in the case of acute stroke. These data confirm the severe suffering of angio- and vasculo-genesis during the acute phase of the disease, and the obvious increase in the levels of S100B, VEGF and CNTF, possibly suggesting their compensatory involvement in neuroprotective mechanisms, which means the reduction of the area of ischemic penumbra.

All patients suspected of IS require brain MRI, and the severity of IS can be related to the volume of the ischemic area. Below we present the imaging results using brain MRI in patients with IS. 


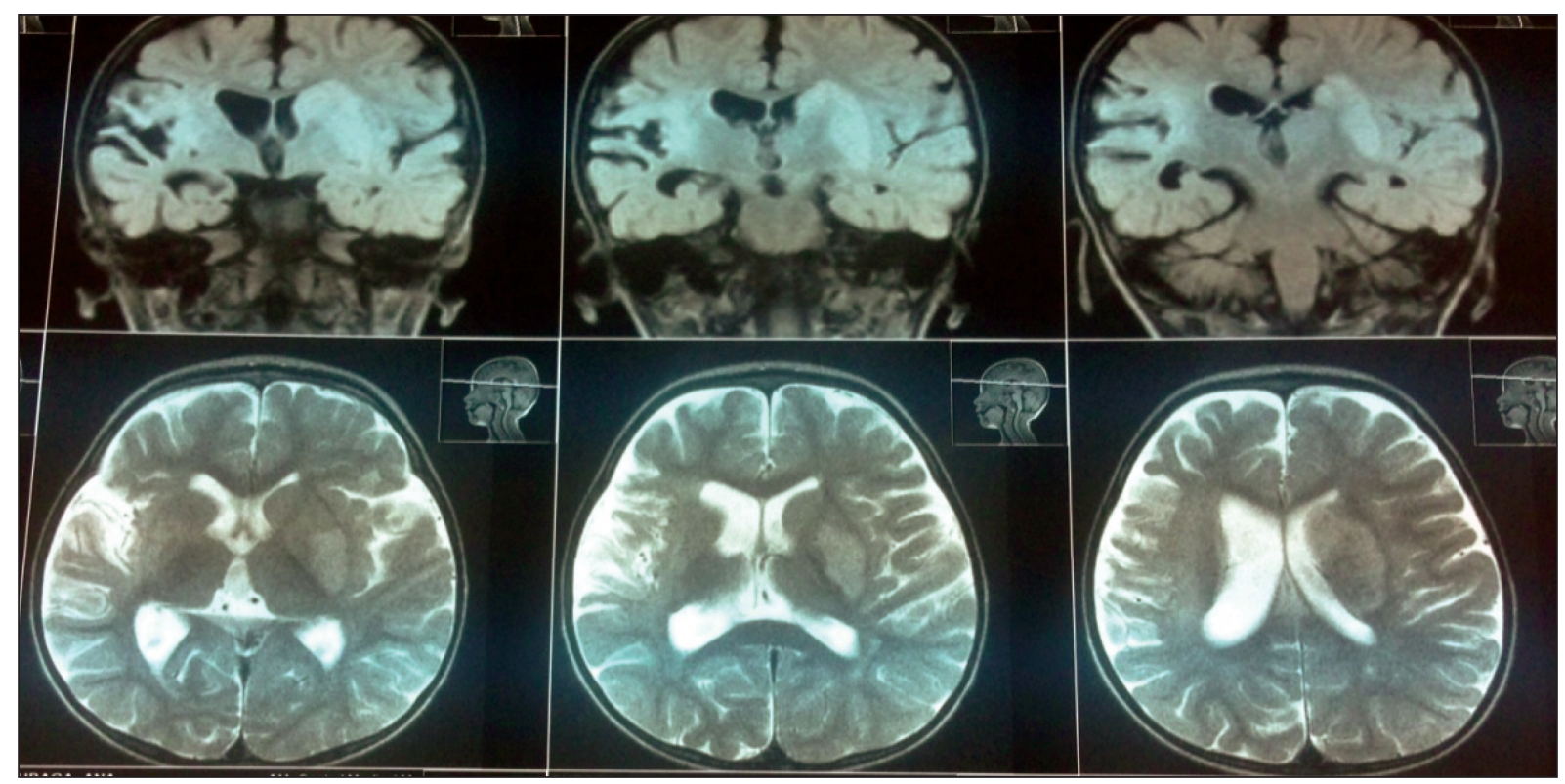

Figure 5. Brain MRI. An area of cytotoxic edema is observed in the region of the basal nuclei on the left, with the predominant involvement of the caput of the caudate nucleus and putamen. Ex vacuo enlargement of the lateral ventricle on the right on the background of post-ischemic cystic changes with gliosis at the level of insula on the right. Signs of diffuse cortical atrophy.
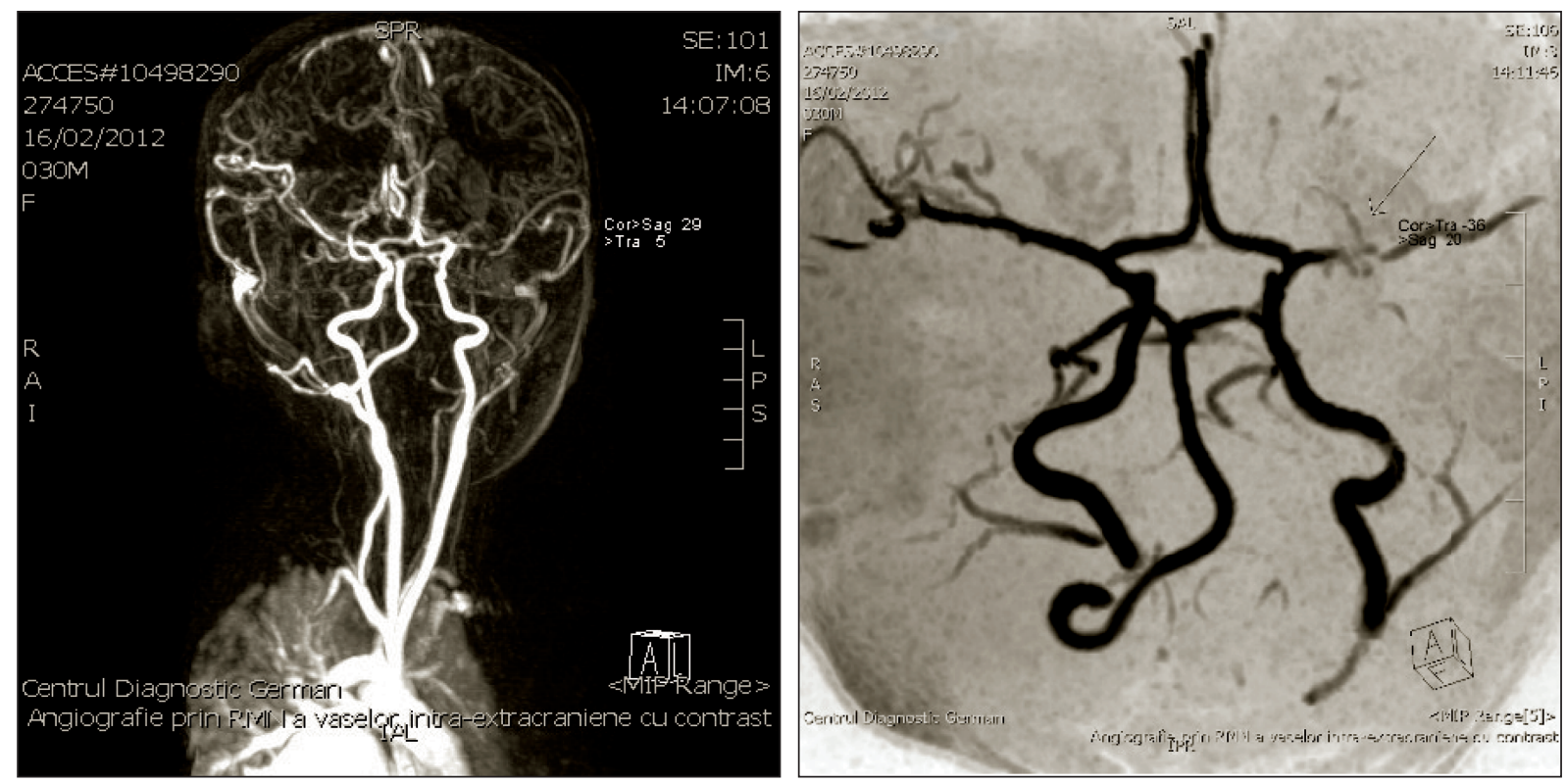

Figure 6. Contrast magnetic resonance angiography at the level of intra- and extracranial vessels. Pronounced stenosis of the M1 segment of the middle cerebral artery on the left is observed. In addition, hypoplasia of the V4 segment of the vertebral artery on the left is observed.

Clinical case 1. Child A.G., aged 2 years and 7 months (boy), urgently admitted for the following symptoms: the patient could not grab things with his left and right hands, does not walk, balance becomes difficult, manifests weakness. On clinical examination, the level of consciousness 12 points Glasgow, 6 points PedNIHSS, symmetrical pupils, pupillary light reflex present, sensitivity is not impaired, jaw jerk reflex is normal, biceps, triceps, brachioradial, patellar and ankle jerk tendon stretch reflexes are elevated on the right; abdominal reflexes are present; pathological reflexes are absent; he does not hold upright position; muscle strength missing in the right half of body; muscle hypertonus in the limbs on the right; meningeal signs negative; retained sphincter functions; speech disorders, lack of contact. The child's status worsens over 2 days, the seizures develop and the child was transferred to the Intensive Care Unit, 

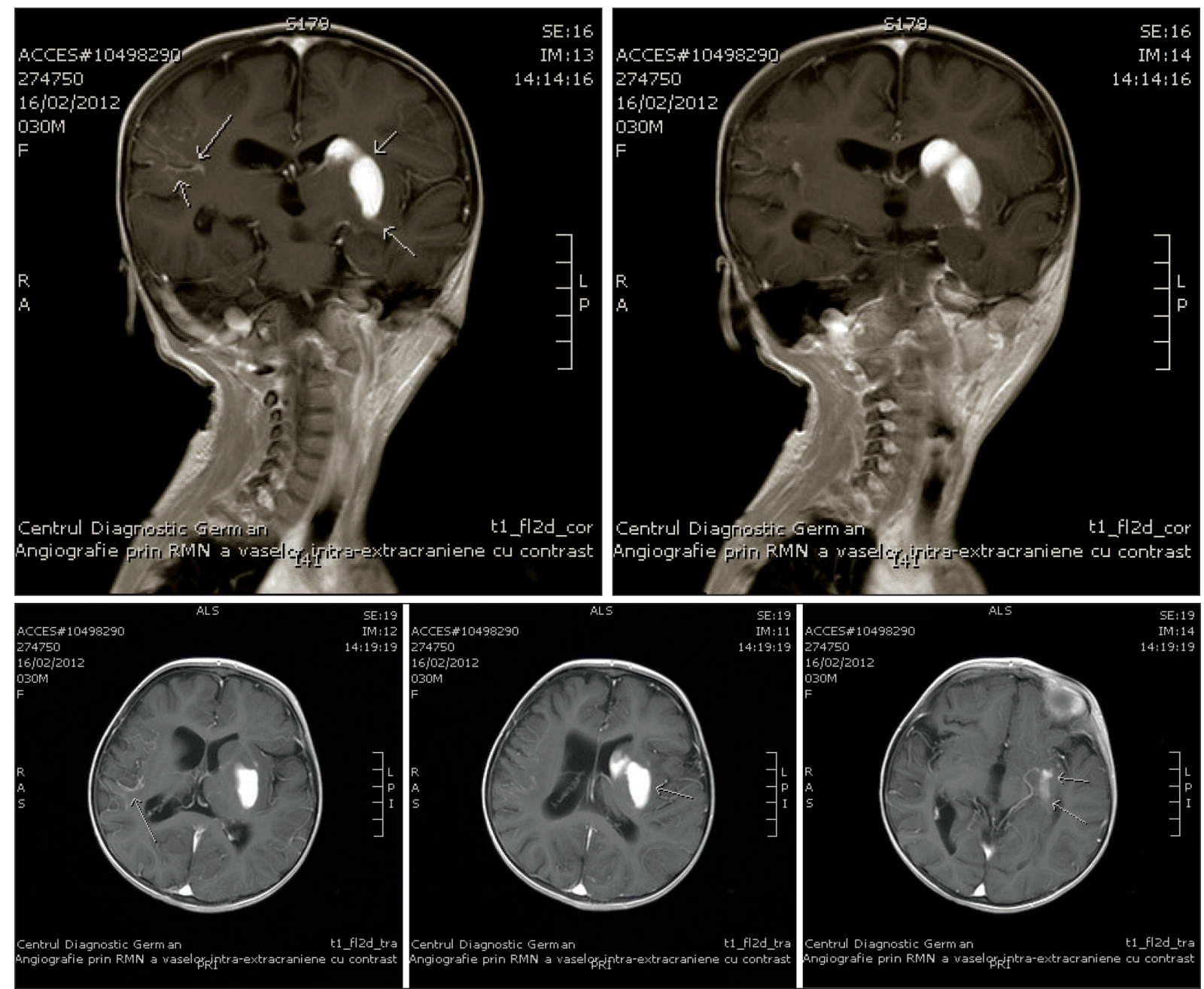

Figure 7. Contrasted brain MRI. T1-weighted frontal images (upper row) and horizontal images (lower row): zones of cerebral ischemia with hemorrhagic transformation at the level of Putamen and Caput of Caudate nucleus on the left.

with suspicion of acute severe middle cerebral artery stroke on the left, hemiparesis on the right, seizures. The level of consciousness was 12 points Glasgow, 6 points PedNIHSS. The molecular-genetic diagnosis was as follows: homozygosity for normal allele FV G1691A, FII G20210A, MTHFR C677T, MTR A2756G and CBS 844ins68; heterozygosity for mutations MTHFR A1298C and MTRR A66G. Brain MRI was performed (Fig. 5, 6, 7). The immunological assays were as follows: S100B $1.082 \mathrm{ng} / \mathrm{mL}$, VEGF $1232.47 \mathrm{pg} / \mathrm{mL}, \mathrm{CNTF} 9.34 \mathrm{pg} / \mathrm{mL}$.

Sometimes, in case of suspected arterio-venous malformation it is necessary to carry out magnetic resonance angiography (MRA), which can help to detect malformation and delimit the ischemic focus.

In the case described above, the diagnosis of large middle cerebral artery IS on the left, at the level of Putamen and Caput of Caudate nucleus was confirmed by imaging, on the background of the prominent stenosis of the M1 segment of the middle cerebral artery on the left and hypoplasia of the V4 segment of the left vertebral artery. These results were correlated with elevated S100B, VEGF and CNTF.

Clinical case 2. Child M. D., aged 14 years (girl), became acutely ill, admitted with symptoms of muscle weakness in her right upper and lower limbs, gait disturbances, tingling in the fingers of both hands, loss of ability to grab and coordination disorders on the right, monotonous speech, delayed answer to questions, decreased memory, diffuse headache, moderate arthralgia in the knees and ankle, wrist and proximal interphalangeal joints with swelling and morning stiffness for about $30 \mathrm{~min}$, fever up to $39^{\circ} \mathrm{C}$, mainly in the evening, for 6 days, and general weakness. She was suspected of severe acute middle cerebral artery stroke on the left, hemiparesis on the right, moderate Raynaud's syndrome. Clinical examination: pale and dry skin, moderate bitter rash, dry lips with cracks, moderate pasty of the lower limbs, swelling and limitation of the movements in interphalangeal and metacarpophalangeal joints, elbows, 

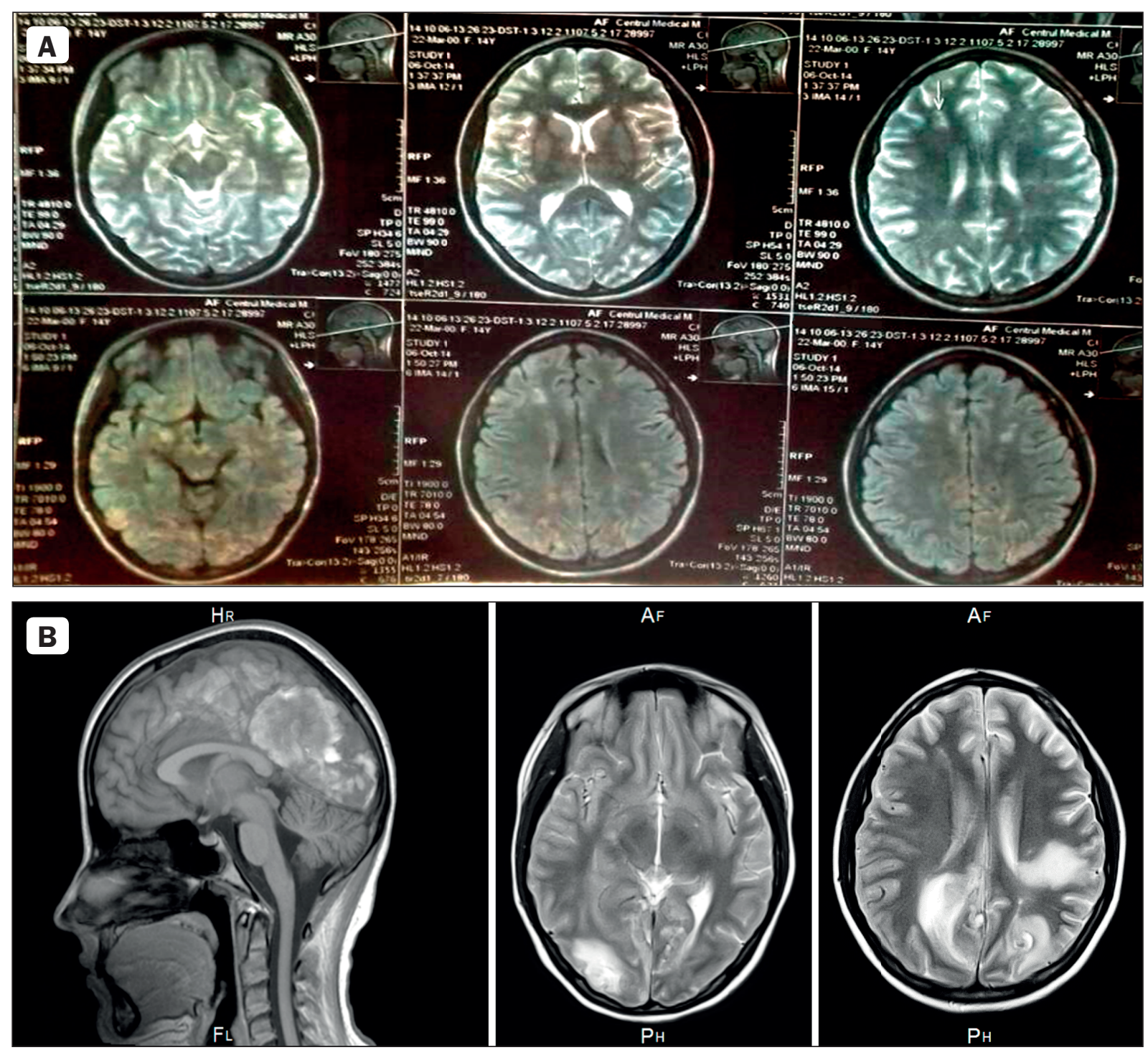

Figure 8. Brain MRI. A. T2-weighted images (upper row), FLAIR/TIRM (lower row) sequences. Multiple ischemic foci with hemorrhagic component in the frontal, parietal and occipital lobes bilaterally. B. T1 (sagittal) and T2-weighted sequences. Multiple foci of hemorrhagic lesions, with pronounced adjacent edema. Data suggestive for diffuse cerebral vasculitis with multiple areas of ischemia with a hemorrhagic component in the parietal and occipital lobes bilaterally and at the level of thalamus on the left $(8 \times 16 \mathrm{~mm})$. Subacute chronic subdural hematoma at the right parietal occipital hemisphere, with transverse diameter on the median line up to $18 \mathrm{~mm}$. Multiple microhemorrhages.

knees and talocrural joints. Neurological examination: state of consciousness preserved, $14-15$ points Glasgow, 6 points NIHSS, convergence diminished, horizontal nystagmus present, sensitivity diminished on the right. In carrying out Barre test, at the right leg there was a slight instability, diminished muscle strength and tone on the right, at right upper limb 4 points on Charles Rousher scale, at right lower limb 3 points; Romberg's test instability; walking disordered, pull the right leg; coordination testing with problems on the right side; stretch tendon reflexes (STR) at the upper and lower limbs diminished on the left side $\mathrm{D}>\mathrm{S}$, hyperreflexia. Brain MRI was performed (Fig. 8). The results of immunological assay were as follows: S100B $1.024 \mathrm{ng} / \mathrm{mL}$, VEGF $1242.37 \mathrm{pg} / \mathrm{mL}$, CNTF $20.26 \mathrm{pg} / \mathrm{mL}$.

In the case described above, the diagnosis of large middle cerebral artery IS on the left was confirmed; there were also noted multiple ischemic foci with a hemorrhagic component in the frontal - parietal occipital lobes bilaterally. Also, a subacute subdural hematoma on the right, as well as a diffuse cerebral vasculitis were diagnosed. These results were correlated with increased levels of S100B, VEGF and CNTF.

Clinical case 3. Child B.L., aged 14 months, became acutely ill after a mild head injury, caused by accidental fall from a height of about $50 \mathrm{~cm}$. The onset 


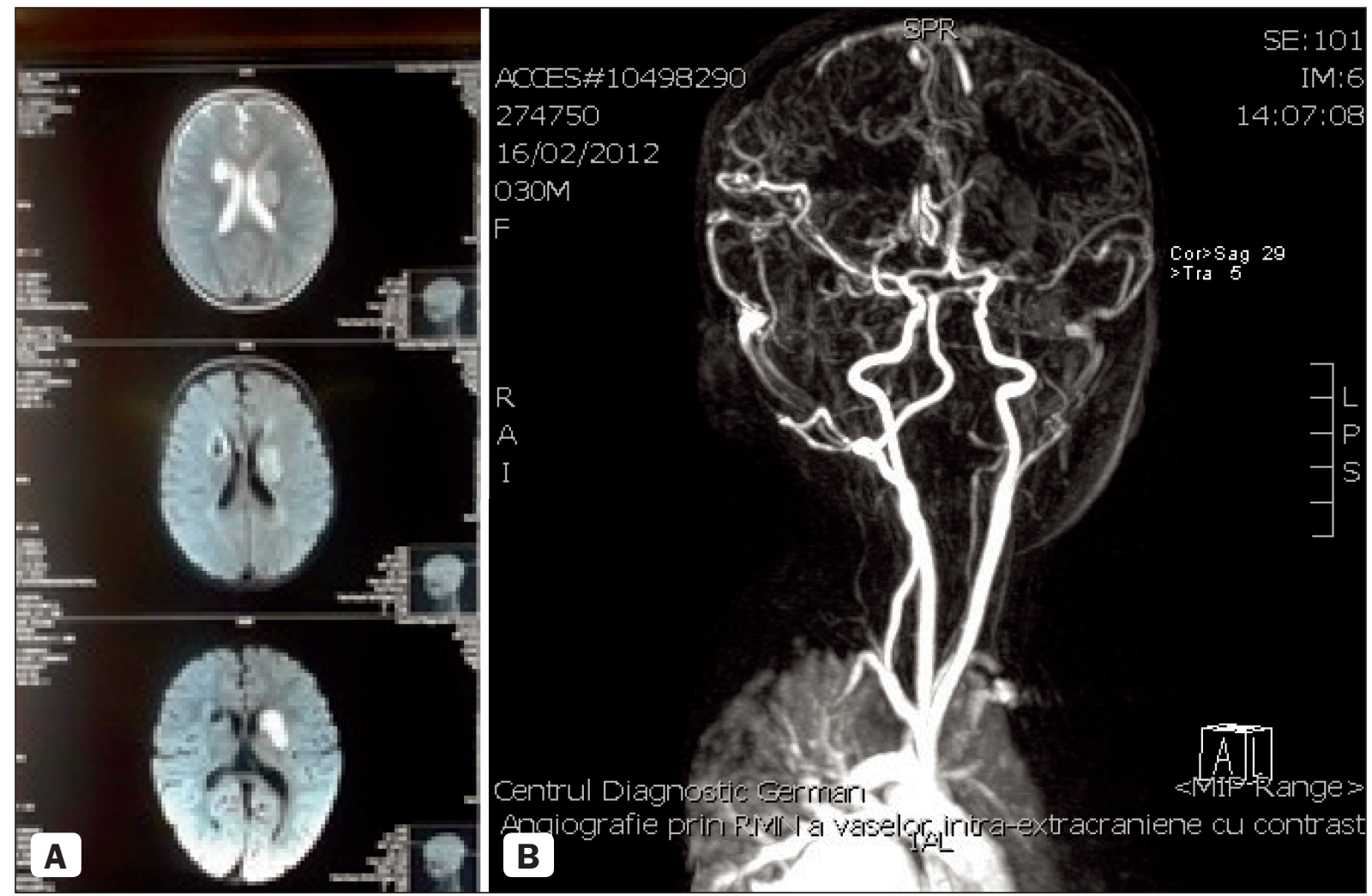

Figure 9. Brain MRI. A. T2-weighted FLAIR/TIRM: Cerebral early acute/subacute ischemia localized at the level of basal ganglia on the left. B. Brain MRA. Segmental stenosis M1 of the middle cerebral artery (MCA) on the left. Hypoplasia of distal segment (V4) of the left vertebral artery.

of disease was with acute hemiparesis on the right and motor focal seizures. There were also symptomatic seizures with focal motor signs. The child was suspected of acute middle cerebral artery stroke on the left. Neurological examination: disordered state of consciousness, 12-13 points Glasgow, cranial nerves without pathological signs, increased muscle tone on the right, i. e., hemiparesis on the right. A score of 7 points on the PedNIHSS scale. Neuro sonographic examination revealed in the thalamic projection on the left a solid formation $28 \times 33 \mathrm{~mm}$, and at the level of the anterior horn on the right a solid formation $12 \times 10$ mm. Brain MRI and MRA were performed (Fig. 9). The results of immunological assay were the follows: S100B $2.737 \mathrm{ng} / \mathrm{mL}$, VEGF 981.23 pg/mL, CNTF $9.46 \mathrm{pg} / \mathrm{mL}$.

The diagnosis of acute stroke in the basal ganglia on the left, on the background of segmental MCA stenosis M1 on the left, with hypoplasia of the distal segment (V4) of the left vertebral artery was established. Stroke has a major impact on long-term neurological outcome, and the levels of immune-based biomarkers can help to assess the clinical evolution of the patient. In the absence of treatment, the most serious results occur in patients who have occlusions of the distal internal carotid artery, proximal middle cerebral artery and basilar artery. In the case described above, the patient's severe health status correlated with elevated levels of S100B, VEGF and CNTF, which confirms the hypothesis of the rapid release of these markers into the bloodstream due to increasing permeability of the blood-brain-barrier in acute IS in children.

Some biomarkers were also studied 6 months after suffering IS, including S100B and VEGF. Protein $\mathrm{S} 100 \mathrm{~B}$, also known as calcium-binding B protein, was found to be higher in children from SS, with an average level of $0.30 \pm 0.022 \mathrm{pg} / \mathrm{mL}$, ranging from $0.16 \mathrm{pg} / \mathrm{mL}$ to $0.81 \mathrm{pg} / \mathrm{mL}$. In CS the level of this protein was relatively stable, i.e., $0.17 \pm 0.001 \mathrm{pg} / \mathrm{mL}$, without large variations $(0.16-0.18 \mathrm{pg} / \mathrm{mL})$. Based on the results obtained, we showed a statistically significant difference between samples $(F=16.948$, p<0.001) (Fig. 10).

The analysis of the level of the S100B protein 6 months after suffering an IS found a significant decrease in the mean values of this pro-inflammatory cytokine, confirmed by a statistically significant difference $(t=2.702, p<0.01)$ (Fig. 11). In Fig. 11, significantly increased values of $\mathrm{S} 100 \mathrm{~B}$ protein in the acute period of the pathology are presented, highlighting the involvement of pro-inflammatory mediators that contribute to cellular edema, increased cerebral toxicity 


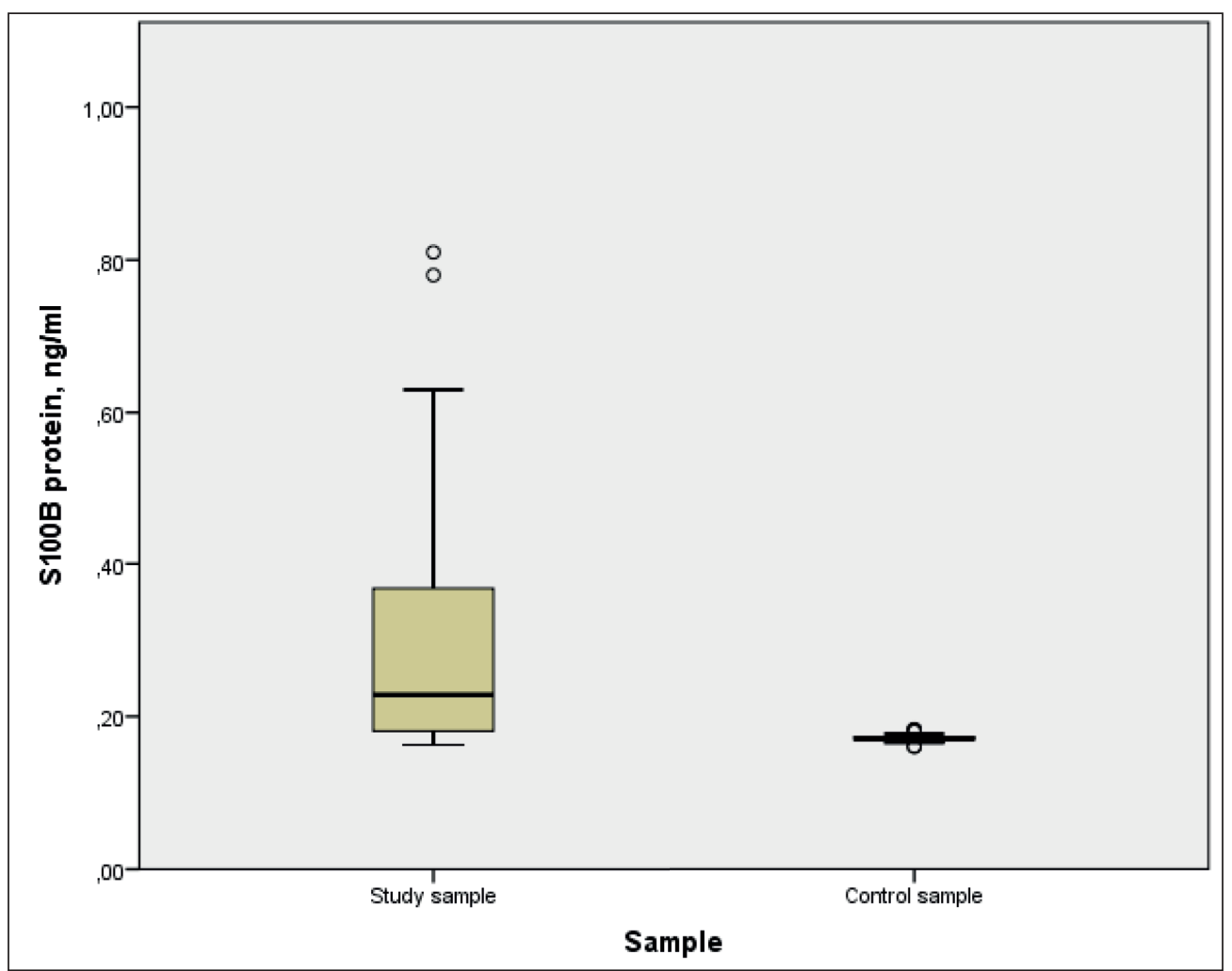

Figure 10. Level of S100B protein 6 months after IS, study sample and control sample, pg/mL.

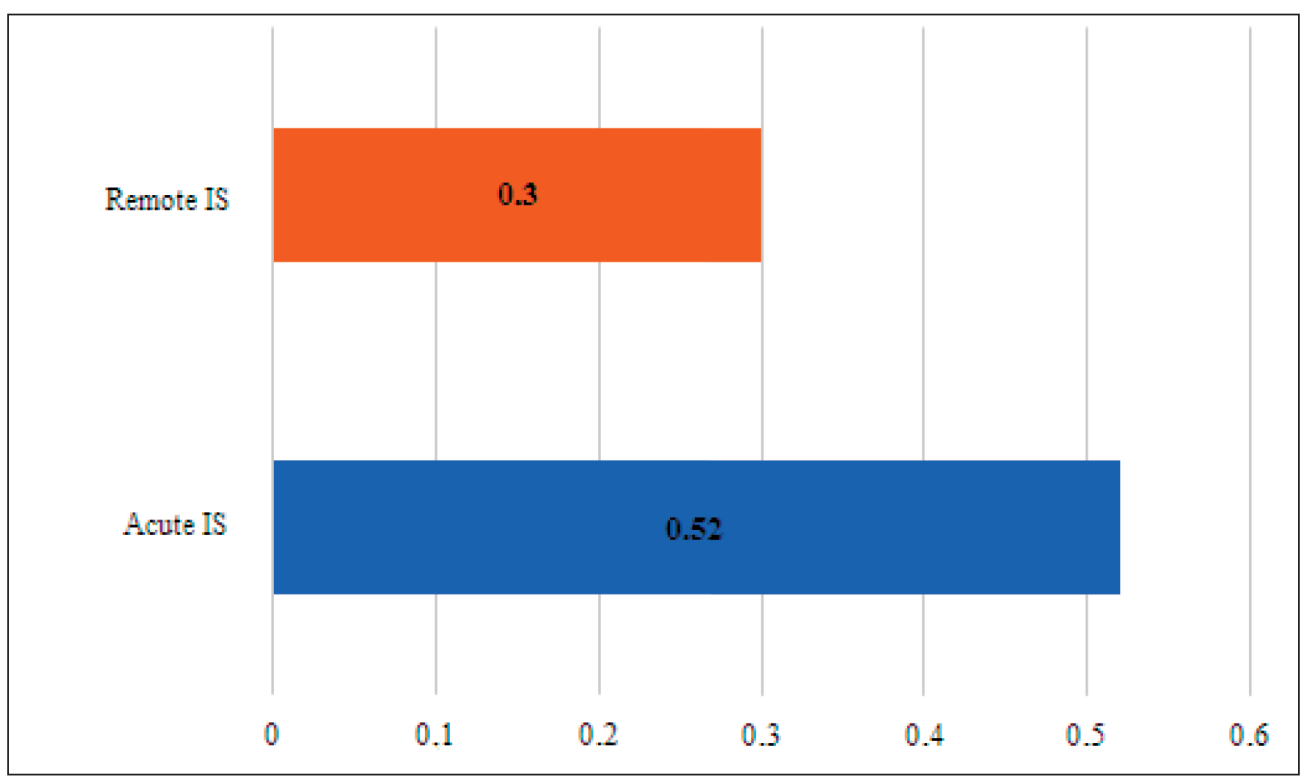

Figure 11. Mean level of S100B protein in children after IS over time, in the acute period and after 6 months, $\mathrm{pg} / \mathrm{mL}$.

and epileptoid genesis. However, stable elevated S100B protein level over time after suffering a stroke, but lower than in acute phase, suggests its involvement in the recovery of brain neurons and axons.

The average level of VEGF in the study sample 6 months after suffering an IS exceeds twice that of the control sample. Thus, in the study group we found an average VEGF level of $374.96 \pm 19.506 \mathrm{pg} / \mathrm{mL}$, with a maximum level of $792.94 \mathrm{pg} / \mathrm{mL}$, and in the control sample the level of $170.13 \pm 6.451 \mathrm{pg} / \mathrm{mL}$. A statistically significant difference $(\mathrm{F}=55.240, \mathrm{p}<0.001)$ can also be seen from the diagram below (Fig. 12).

As with the S100B protein, the VEGF level, assessed 6 months after IS, decreased, but did not 


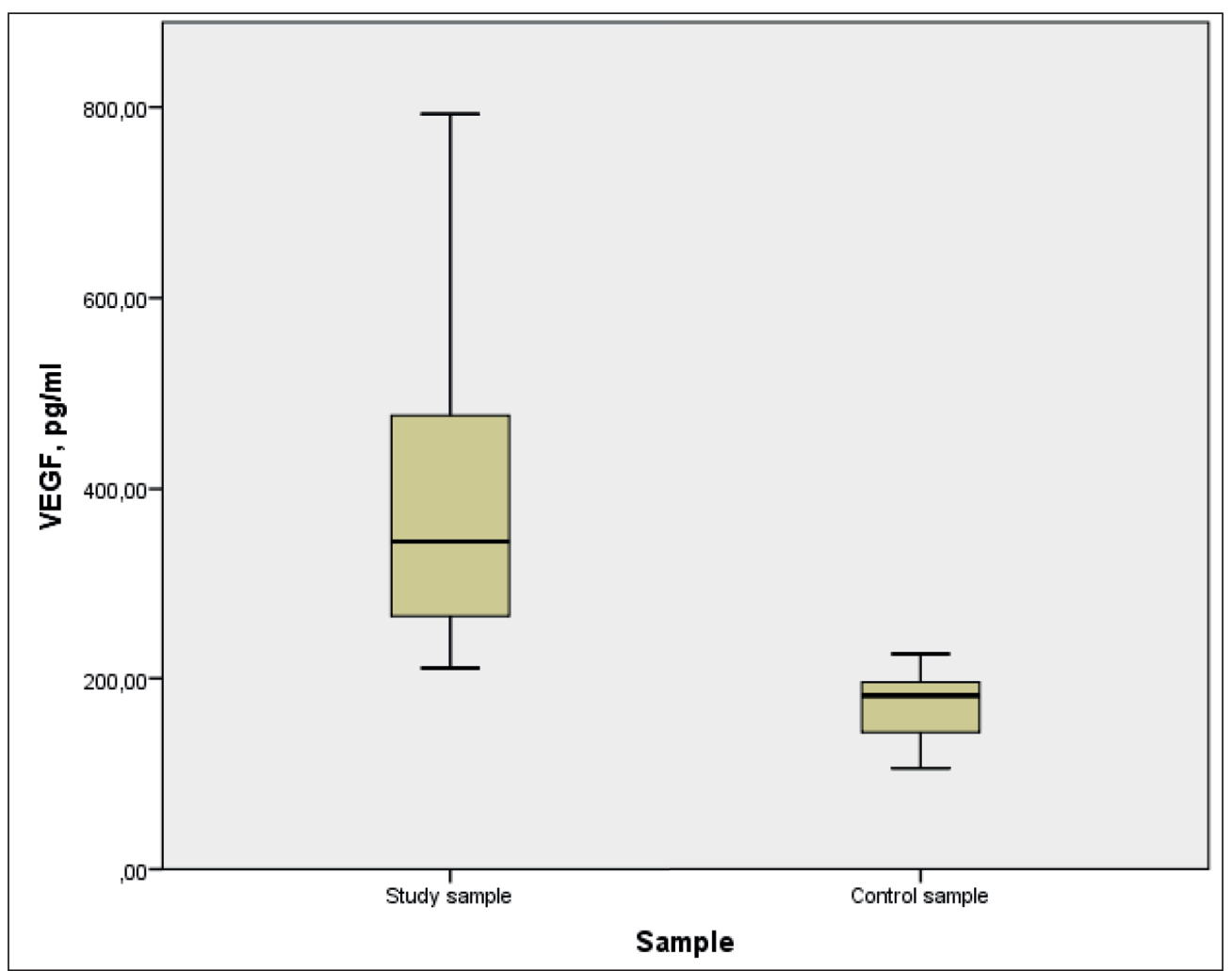

Figure 12. Mean serum levels of VEGF 6 months after IS

in study sample compared to the sample of "practically healthy" children, $\mathrm{pg} / \mathrm{mL}$.

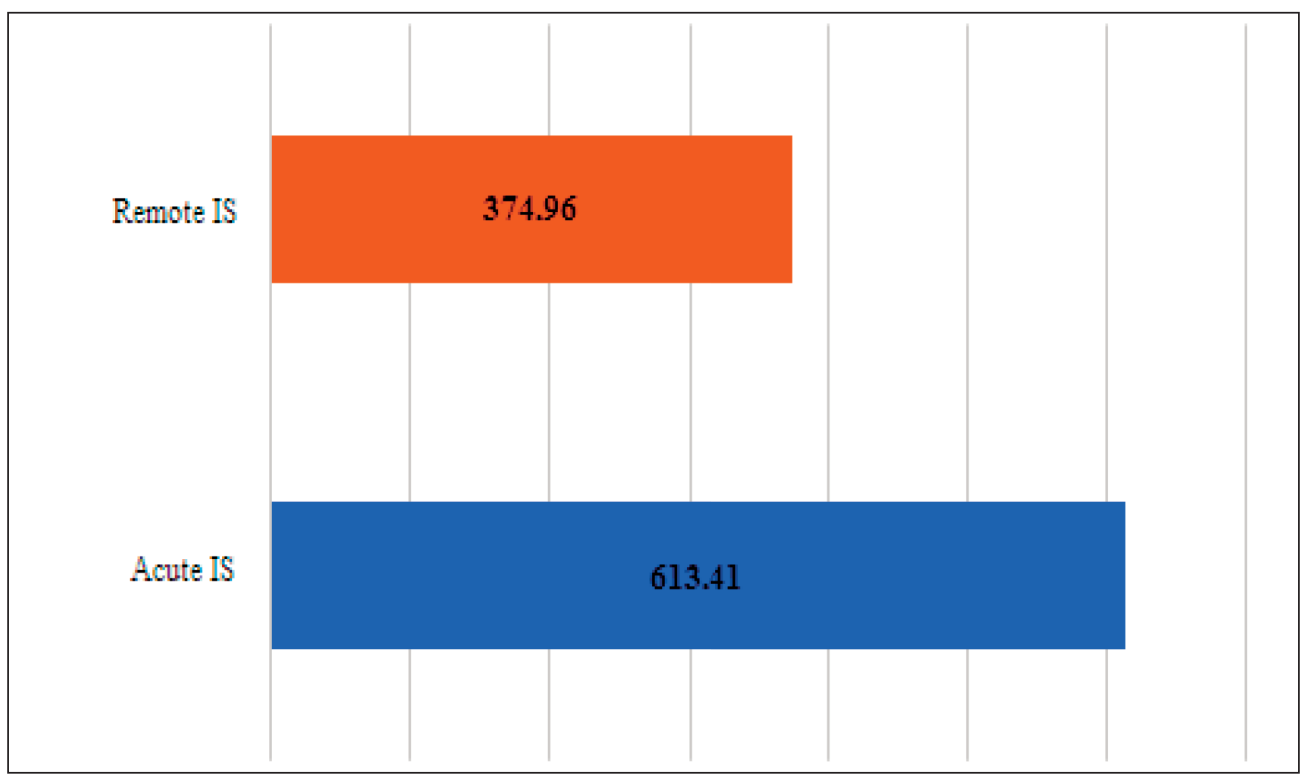

Figure 13. Mean level of VEGF in children after IS over time, in acute period and after 6 months, pg/mL.

return to the values of "practically healthy" children, that supports significant statistical difference over time $(\mathrm{t}=7.104, \mathrm{p}<0.01)$ (Fig. 13).

The maintenance of elevated VEGF levels in children after IS, but significantly lower compared to the acute period, confirms the involvement of this marker in ischemic remodeling and the recovery of vascularization by stimulating the formation of blood vessels, and confirms the importance of VEGF in neuro regeneration. Correlations between the $\mathrm{S} 100 \mathrm{~B}$ protein and remote value of VEGF were not attested, as in the study sample $r_{\mathrm{xy}}=-0.088$, and in control sample $r_{\mathrm{xy}}=0.195$. 


\section{Discussion}

Numerous studies ${ }^{9}$ have shown S100B protein as the most studied biomarker in IS in children and adults, which has intracellular and extracellular properties. At the intracellular level, the S100B protein is part of calcium homeostasis, thus transferring signals from secondary messengers ${ }^{11}$. In this context, under experimental conditions, it has been determined that the $\mathrm{S} 100 \mathrm{~B}$ protein is involved in cell differentiation and cell cycle progression, as well as in inhibition of apoptosis. At the extracellular level, under normal and pathological conditions, the S100B protein is involved in the promotion of neurogenesis and neuronal plasticity, neuromodulating processes, enhancing memory and learning ${ }^{10,11}$. However, the physiological effects and functions of the S100B protein have been shown to be dependent on its serum concentrations, i.e., lower concentrations are beneficial for the normal functioning of the human organism and increased concentrations are correlated with harmful effects. Under experimental conditions, it has been shown that the increase in extracellular levels of the S100B protein lead to neuronal dysfunction up to cell death caused by the development of an inflammatory response that stimulates astrocytes and microglia ${ }^{12}$. Further, S100B protein determines the recruitment and production of pro-inflammatory cytokines, with a subsequent increase in extracellular calcium levels and the activation of nitrous oxide, causing harmful effects ${ }^{13,14}$. Studies on S100B in IS reveal that the level of S100B protein in patients with global ischemic brain injury can increase dramatically. In IS with severe neurological manifestations the serum level of the S100B protein is raised ${ }^{15}$. Over the past decade, S100B protein becomes a candidate peripheral biomarker of the permeability of the blood-brain barrier and central nervous system (CNS) lesions. The increased levels of S100B protein reliable reflect the presence of neuropathological conditions, including IS. The S100B protein in the serum of patients with ischemic brain damage will rapidly increase within 6 hours of ischemic injury. Studies ${ }^{16}$ have shown that higher levels of S100B protein in serum correlates with higher risk of patients with IS. It is also reported that the S100B protein could predict the outcome of patients with $\mathrm{IS}^{17}$. In the presented study, in children with IS there were determined substantially elevated levels of S100B protein in the acute phase of the disease, which confirms the involvement of this protein in ischemic processes and substantiate its importance in assessing the severity of the disease, as well as the neurological remote outcome.

In one study ${ }^{18}$ it was investigated the role of the vascular endothelial growth factor (VEGF), which was recently associated with the ciliary neurotrophic factor (CNTF) as an important biomarker in IS. The authors suggest that CNTF mediates neurogenesis and anti-inflammatory processes ${ }^{19}$. These data recently were confirmed on animal models ${ }^{20}$. The same opinion was showed also by other authors ${ }^{21}$.

To date, there is no evidence of the role of CNTF plasma level in stroke, although circulating levels of this neurotrophin have been shown to be of greater importance in amyotrophic lateral sclero$\mathrm{sis}^{21,22}$. However, the present study revealed significantly increased levels of CNTF in patients with IS, which is correlated with the severity of the process. These data confirm the involvement of the CNTF in cerebral ischemia in children and its role in promoting neuroplasticity in the early stage of cerebral ischemia.

Studies on the systemic using of VEGF antagonists suggest that endogenous VEGF may contribute to collateral ischemic remodeling ${ }^{23,24}$. It has been demonstrated the participation of VEGF in the processes of atherosclerosis, atherogenesis, cerebral edema, neuroprotection, neurogenesis, angiogenesis, postischemic phenomenon with subsequent repair of vessels, as well as their effects on transplanted stem cells in experimental stroke. Most of these processes involve VEGF-A and its receptor VEGFR-2. Thus, VEGF-B, placental growth factor and VEGFR-1 were involved only in individual cases. VEGF signaling pathways are potentially important targets for stroke treatment in acute and chronic phases ${ }^{25}$.

VEGF-A is a primary mediator of cerebral angiogenesis, which has elevated levels after IS in rodents and humans ${ }^{26}$. However, it is expressed by low levels in the absence of angiogenesis, as in the adult neuroectoderm. On the other hand, inducing angiogenesis by growth factors, i.e., pro-angiogenesis, could be a rational therapy for stroke patients. VEGF is important in branched morphogenesis. The data presented by same authors ${ }^{26}$ support the hypothesis that collateral density and vascular branching are closely related ${ }^{26}$. In our study group, the level of VEGF in the acute phase of the process was higher than in the control group, which is consistent with the results of other experimental and clinical studies.

Neuro-regeneration is determined by the ability to regenerate tissues, cells or cellular products ${ }^{27}$. Such mechanisms may include the generation of new neurons, alteration of glia, axons, myelin or synapses. The number and diameter of pre-existing collaterals in healthy tissues and their remodeling capacity are critical determinants of the severity of ischemic lesion as a result of arterial obstruction. While the molecular processes that regulate collateral remodeling in ischemia begin to be understood, nothing is known 
about when the native collaterals and responsible signaling mechanisms are formed. Collateral expansion in ischemia requires the proliferation of endothelial and vascular wall cells, recruitment of leukocytes and remodeling of the extracellular matrix. Evidence suggests that VEGF participate in these processes. However, the results of studies of exogenous VEGF, which suggest that it may increase the size of the collaterals, are inconsistent ${ }^{28,29}$. Multiple isoforms of VEGF, receptors and intracellular pathways, plus inaccessibility of collateral circulation, make it difficult to determine a direct effect on collateral remodeling. Most studies comprised only one form of VEGF with limited control of its concentration, which resulted in defective neovascularization, tissue edema and impaired vessel growth ${ }^{30,31}$. VEGF levels have been shown to be increased in children with IS, especially those with severe course of the process. Due to this fact, we can confirm the involvement of the marker in the promotion of angiogenesis, as well as in the vascular remodeling during the first hours of cerebral infarction, which denotes the need for therapeutic correction of these complex processes.

The most important factors that determine the outcome of patients with acute stroke include the severity of neurological symptoms, the artery involved, the size of the infarction's focus, as well as the immunological results of the biomarkers investigated ${ }^{32}$. Depending on the values of the biomarkers investigated and the dimensions of the infarction's focus, the severity of neurological symptoms can be assessed. The more severe symptoms, the higher levels of biomarkers. Patients with mild IS have mild symptoms and levels of S100B protein, VEGF and CNTF. These patients fully recover, and the correlation of the biomarkers' levels to the size of the infarction is very important. The volume of ischemic damaged brain tissue is a major determinant of clinical and immunological outcomes in IS. Some studies established that MRI is the best method for determining the size of the infarction's focus in the early and late stages of $I^{2}$. Data from the current study show that if the dimensions of infarction's focus involve approximately $1 / 3$ of the MCA perfusion area or more ( $100 \mathrm{ml})$, the evolution is severe, as well as the levels of biomarkers investigated are higher.

Patients with a larger ischemic focus have severe neurological deficits, and the values of the biomarkers investigated show prominent changes. These patients have an increased probability for poor neurological and general outcome, i. e., death or neurologic, motor and verbal sequelae, if the treatment is not successful.

Acute IS is a heterogeneous disease, and the elevated values of the biomarkers investigated show various results related to the severity of the ischemic focus ${ }^{33,34}$. The ischemic focus can be investigated using MRI, and the estimation of immunological biomarkers may suggest data on IS mechanisms, which is strongly supported by the results of the presented study. Thus, patients with severe strokes with pronounced neurological symptoms have increased levels of S100B, VEGF and CNTF, while in medium and mild stroke these values are lower. Thus, the main role of study of IS biomarkers is to assess the degree of correlation with the severity of the process, with the dimensions and topography of the cerebral ischemic focus detected on the MRI sequences. It is necessary to further investigate the involvement of these markers in determining the therapeutic strategy to improve early and remote neurological outcome ${ }^{35}$.

In addition, the application of tests of S100B, CNTF and VEGF greatly facilitates the accuracy of diagnosis, the appreciation of the severity of the process and the prognosis of remote neurological outcome. The probability of detection of neurological problems increases with prominent increasing of values of investigated biomarkers, i.e., S100B, CNTF and VEGF values, which suggests therapeutic corrections with medicaments administered as early as possible in all patients suspected of IS.

\section{Conclusions}

In the acute period of IS we observed a significant increase of values of certain markers (S100B, VEGF and CNTF), which determine their role as biomarkers involved in ischemic brain processes. The results of the study suggest that by targeting some markers of IS (S100B, VEGF and CNTF) it is possible to analyze the inflammation, neuroprotection, vasculo- and neuro-regeneration from the onset of cerebral ischemia, in order to decrease the risks of developing early and remote neurological complications and to predict their development.

With the updating of literature on biomolecular topics, the views on biomarkers in IS have achieved a significant revision in recent years. In addition to the diagnostic and prognostic role of inflammatory markers, many other molecules and biological factors have been included in the sphere of interest, including tissue cytokines, growth factor-like molecules, hormones and micro-RNA. To date, biomarkers are a possible tool in diagnosing and assessing the course of IS from the onset, as well as assessment of its pathogenesis and outcome. Many molecules are still under investigation and can become promising and encouraging biomarkers. Experimental and clinical research of biomarkers promotes new discoveries in pediatric neurology, to improve the diagnosis and treatment of IS in children. 


\section{Author Contributions:}

Conceptualization, M.S. and S.H.; methodology, N.R.; software, E.C.; validation, C.C. and N.R.; formal analysis, S.H.; investigation, M.S.; resources, N.L.; data curation, M.S. and S.H.; writing-original draft preparation, M.S.; writing-review and editing, M.S, S.H., N.R.; visualization, S.H. and N.R.; supervision, N.R.; project administration, S.G. All the authors have read and agreed with the final version of the article.

\section{Compliance with Ethics Requirements:}

„The authors declare no conflict of interest regarding this article"

"The authors declare that all the procedures and experiments of this study respect the ethical standards in the Helsinki Declaration of 1975, as revised in 2008(5), as well as the national law. Informed consent was obtained from all the patients included in the study"

"No funding for this study"

\section{Acknowledgements:}

None

\section{References}

1. Rivkin MJ, Bernard TJ, Dowling MM, Amlie-Lefond C. Guidelines for urgent management of stroke in children. Pediatr Neurol. 2016; 56:8-17.

2. Kirton A, de Veber G. Paediatric stroke: pressing issues and promising directions. Lancet Neurol. 2015; 14:92-102.

3. Mallick AA, Ganesan V, Kirkham FJ, et al. Childhood arterial ischemic stroke incidence, presenting features, and risk factors: a prospective population-based study. Lancet Neurol. 2014; 13:35-43

4. Bigi S, Fischer U, Wehrli E, et al. Acute ischemic stroke in children versus young adults. Ann Neurol. 2011; 70(2):24554.

5. Hicks VJ Jr, Black LM. Evaluation, identification, and management of pediatric strokes in the emergency department using a pathway algorithm. J Emerg Nurs. 2013; 39:132-7.

6. Coelho Junior HJ, Gambassi BB, Diniz TA, et al. Inflammatory mechanisms associated with skeletal muscle sequelae after stroke: role of physical exercise. Mediators of Inflammation. 2016; 2016: 19.

7. Elkind MS. Inflammatory markers and stroke. Current Cardiology Reports. 2009;11(1):12-20.

8. Hadjiu S. The remedy role of neurotrophic factor (BDNF) in perinatal hypoxic-ischemic injury. J Romanian Child and Adolescent Neurology and Psychiatry. 2010; 13(4): 33-48.

9. Ambree O, Bergink V, Grosse L, et al. S100B serum levels predict treatment response in patients with melancholic depression. Int J Neuropsychopharmacol. 2016; 119:pyv103.

10. Bouvier D, Fournier M, Dauphin JB, et al. Serum S100B determination in the management of pediatric mild traumatic brain injury. Clin Chem. 2012; 58:1116-1122.

11. Hicks VJ Jr, Black LM. Evaluation, identification, and management of pediatric strokes in the emergency department using a pathway algorithm. J Emerg Nurs. 2013; 39:132-7.

12. Mureșanu D. Factorii neurotrofici. București: Libripress. 2002, p. 85-113, 131-151, 163-168, 223-299.
13. Ding J, He Z, Ruan J, et al. Role of ciliary neurotrophic factor in the proliferation and differentiation of neural stem cells. J Alzheimer's Disease. 2013; 37(3): 587-592.

14. Calcagnile O, Anell A, Unden J. The addition of S100B to guidelines for management of mild head injury is potentially cost saving. BMC Neurol. 2016; 16:200.

15. Beer C, Blacker D, Bynevelt M, et al. Systemic markers of inflammation are independently associated with $\mathrm{S100B}$ concentration: results of an observational study in subjects with acute ischemic stroke. J Neuroinflammation. 2010; 7:71.

16. Bloomfield SM, McKinney J, Smith L, Brisman J. Reliability of $\mathrm{S} 100 \mathrm{~B}$ in predicting severity of central nervous system injury. Neurocrit Care. 2007; 6:121-138.

17. Helánová K, Pařenica J, Jarkovský J, et al. S-100B protein elevation in patients with the acute coronary syndrome after resuscitation is a predictor of adverse neurological prognosis. Vnitr Lek. 2012; 58:266-272.

18. Kearney JB, Kappas NC, Ellerstrom C, et al. The VEGF receptor flt-1 (VEGFR-1) is a positive modulator of vascular sprout formation and branching morphogenesis. Blood. 2004; 103: 4527-4535.

19. Bechstein M, Häussler U, Neef M, et al. CNTF-mediated pre-activation of astrocytes attenuates neuronal damage and epileptiform activity in experimental epilepsy. Exp. Neurol. 2012; 236(1): 141-150.

20. Liu F, Mccullough LD. Inflammatory responses in hypoxic ischemic encephalopathy. Acta Pharmacologica Sinica. 2013, 34(9): 1121-1130.

21. Garcia N, Santafe MM, Tomas M, et al. Exogenous ciliary neurotrophic factor (CNTF) reduces synaptic depression during repetitive stimulation. J Peripheral Nerv System. 2012, 17(3): $312-323$

22. Ferrara N, Gerber HP, Le Couter J. The biology of VEGF and its receptors. Nat Med. 2003; 9:669-676.

23. Mackenzie F, Ruhrberg C. Diverse roles for VEGF-A in the nervous system. Development. 2012; 139: 1371-1380.

24. Grundmann S, Piek JJ, Pasterkamp G, Hoefer IE. Atherogenesis: basic mechanisms and therapeutic stimulation. Eur J Clin Invest. 2007; 37:755-766.

25. Wang L, Zhang Z, Wang Y, et al. Treatment of stroke with erythropoietin enhances neurogenesis and angiogenesis and improves neurological function in rats. Stroke 2004; 35:1732-1737.

26. Du H, Li P, Pan Y, Li W, et al. Vascular endothelial growth factor signaling implicated in neuroprotective effects of placental growth factor in an in vitro ischemic model. Brain Research. 2010; 1357:1-8.

27. Wagenaar N, de Theije CGM, de Vries LS, et al. Promoting neuro-regeneration after perinatal arterial ischemic stroke: neurotrophic factors and mesenchymal stem cells. Pediatric Research. 2018; 83: 372-384.

28. Baburamani AA, Castillo-Melendez M, Walker DW. VEGF expression and microvascular responses to severe transient hypoxia in the fetal sheep brain. Pediatric Research. 2013; 73(3): 310-316.

29. Hadjiu S. The role of the neurotrophic factor BDNF in perinatal hypoxic-ischemic encephalopathy. International Journal of Integrative and Bio-regulatory Medicine „Physiological Regulating Medicine“. 2011: 13-21.

30. van Velthoven CT, Kavelaars A, van Bel F, Heijnen CJ. Mesenchymal stem cell treatment after neonatal hypoxic-ischemic brain injury improves behavioral outcome and induces neuronal and oligodendrocyte regeneration. Brain Behav Immun. 2010; 24: 387-393. 
31. McCann SK, Cramond F, Macleod MR, Sena ES. Systematic review and meta-analysis of the efficacy of interleukin-1 receptor antagonist in animal models of stroke: an update. Translational Stroke Research. 2016; 7(5): 395-406.

32. Uivarosan D, Tit DM, Iovan C, et al. Effects of combining modern recovery techniques with neurotrophic medication and standard treatment in stroke patients. Science of the Total Environment. 2019; 679: 80-87.

33. Uivarosan D, Abdel-Daim M, Endres L, et al. Effects of a proteic swine extract associated to recovery treatment on functional independence and quality of life in patients post stroke. Farmacia. 2018; 66(5): 826-830.

34. Epingeac ME, Gaman MA, Diaconu C, Gad M, Gaman AM. The evaluation of oxidative stress in obesity. Rev Chim (Bucharest). 2019;70(6):2241-2244.

35. Dobrica EC, Gaman MA, Cozma MA, Bratu OG, Pantea Stoian A, Diaconu CC. Polypharmacy in type 2 diabetes mellitus: insights from an internal medicine department. Medicina. 2019;55(8), 436 